Article

\title{
On Flexural Performance of Girder-To-Girder Wet Joint for Lightweight Steel-UHPC Composite Bridge
}

\author{
Shuwen Deng ${ }^{1}$, Xudong Shao ${ }^{1, *}$, Banfu Yan ${ }^{1, *}$, Yan Wang ${ }^{1,2}$ and Huihui $\mathrm{Li}^{3}{ }^{3}$ \\ 1 Key Laboratory for Wind and Bridge Engineering of Hunan Province, Hunan University, \\ Changsha 410082, China; dengsw@hnu.edu.cn (S.D.); yanwang@hnu.edu.cn (Y.W.) \\ 2 Civil Engineering and Engineering Mechanic, Columbia University, New York, NY 10027, USA \\ 3 Department of Civil and Environmental Engineering, the City College of City University of New York, \\ New York, NY 10027, USA; hli004@citymail.cuny.edu \\ * Correspondence: shaoxd@vip.163.com (X.S.); yanbanfu@hnu.edu.cn (B.Y.)
}

Received: 2 January 2020; Accepted: 13 February 2020; Published: 16 February 2020

\begin{abstract}
Joints are always the focus of the precast structure for accelerated bridge construction. In this paper, a girder-to-girder joint suitable for steel-ultra-high-performance concrete (UHPC) lightweight composite bridge (LWCB) is proposed. Two flexural tests were conducted to verify the effectiveness of the proposed T-shaped girder-to-girder joint. The test results indicated that: (1) The T-shaped joint has a better cracking resistance than the traditional I-shaped joint; (2) The weak interfaces of the T-shaped joint are set in the areas with relatively lower negative bending moment, and thus the cracking risk could be decreased drastically; (3) The natural curing scheme for the joint is feasible, and the reinforcement has a very large inhibitory effect on the UHPC material shrinkage; The joint interface is the weak region of the LWCB, which requires careful consideration in future designs. Based on the experimental test results, the design and calculation methods for the deflection, crack width, and ultimate flexural capacity in the negative moment region of LWCB were presented.
\end{abstract}

Keywords: ultra-high-performance concrete (UHPC); steel-UHPC composite bridge; UHPC connections

\section{Introduction}

An accelerated bridge construction $(\mathrm{ABC})$ concept has been proposed in recent years. $A B C$ is a bridge design and construction method that takes full advantage of prefabrication bridge elements, and it has a minimum disturbance to the in-service traffic network of bridge constructions. However, connections are always the focus of attention for precast systems, and also a potential source of future maintenance. The common way for the construction of connections is to increase the reinforcement or to apply the post-tensioning system, while the above schemes extend the on-site construction time, as well as the cost and maintenance.

In order to solve the above problems, it is necessary to improve the structure and material mechanical properties. Thus, a type of ultra-high-performance concrete (UHPC) girder-to-girder joint that makes bridges continuous is proposed in the present study. UHPC is a class of cement-based material, and previous research has demonstrated that it has the excellent properties of anti-freeze, anti-corrosion, and crack resistance performance [1-5], and it has been widely used in bridge construction [6-9]. The use of UHPC material can reduce the bridge weight by about $37-54 \%[10,11]$. A large number of studies and applications have been done on UHPC deck-to-deck joints: Graybeal performed a structural test on a full-scale pi-girder fabricated with the longitudinal joint. In the following year, a series of tests on field-cast UHPC connections between high-performance concrete (HPC) panels were conducted [12]. In 2013, Aaleti et al. published a design guide for precast UHPC waffle deck panel systems and connections [13]. Perry et al. gave the design and details of narrow joints 
used in the Mackenzie River Twin Bridges [14]. Graybeal published a report which provided detailed guidance on the design and deployment of field-cast UHPC connections, including connections of adjacent precast deck panel, precast deck panel to girder, adjacent box beams, and other longitudinal elements [15]. In China, Guan presented a UHPC longitudinal joint flexural test, and the result showed that the cracking strength of the proposed joint could meet the design requirement [16]. Qi [17] investigated the flexural behavior of a UHPC joint in seven UHPC slabs under negative bending moment, in which an innovative method using steel wire mesh was presented to enhance the interface between precast and cast-in-place UHPC at the joints.

As for research of the seismic performance of UHPC joints, Tazarv and Saiidi investigated the UHPC-filled duct connections for accelerated bridge construction of reinforcement concrete (RC) columns in high seismic zones [18]. The above research and applications indicated that UHPC is feasible in prefabricated structures.

However, reports on the treatment of the UHPC girder-to-girder joint that made the bridge continuous are rarely seen. Thus, in the present study, a type of girder-to-girder joint suitable for steel-UHPC composite bridges is proposed and tested. For accelerating bridge construction, the scheme of a fully precast lightweight steel-UHPC composite girder element is also presented. The composite element replaced the normal strength concrete deck of the steel-concrete composite girder with a thinner, tougher, and ultra-high performance concrete (UHPC) deck.

The following section of the paper introduces the design concept of the joint in detail. In order to verify the design, a bending test was conducted on a large scale specimen with two joints (i.e., the first generation T-shaped joint and the traditional I-shaped joint) and is presented in the third section. Then, in the fourth section, the scheme is further optimized (named as the second generation T-shaped joint) and experimental verification was carried out. Finally, the calculation methods of deflection, crack width, and bearing capacity of the proposed design are presented.

\section{Design Aspects}

The fully precast lightweight steel-UHPC composite bridge (LWCB), as shown in Figure 1a, consists of several $\pi$-shaped steel-UHPC composite girder components (Figure 1b). Each prefabricated component is composed of one UHPC panel and two I-shaped steel girders, which are connected by headed studs. In the transverse direction of the LWCB, the prefabricated components are connected by panel-to-panel joints, while in the longitudinal direction, they are assembled together by girder-to-girder joints.

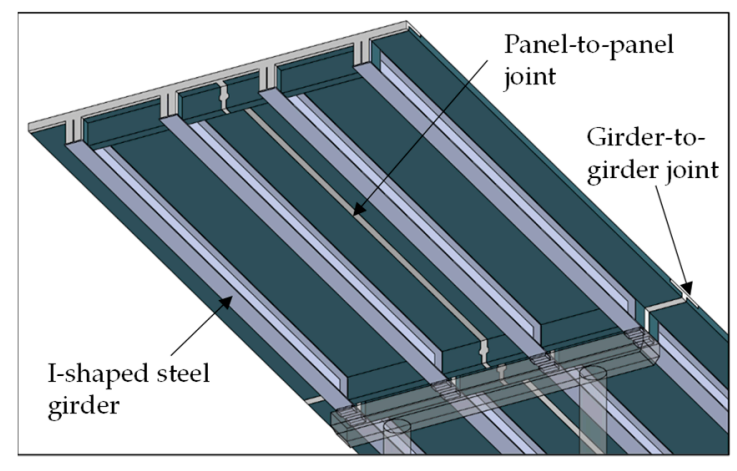

(a)

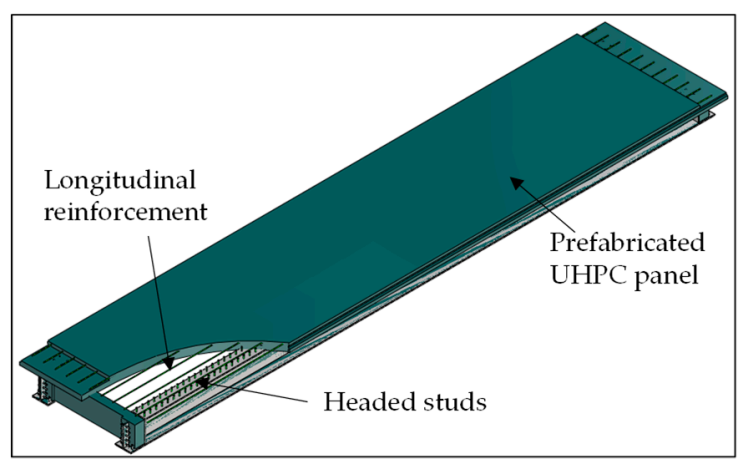

(b)

Figure 1. View of the lightweight steel-ultra-high-performance concrete (UHPC) composite bridge (LWCB): (a) the whole bridge; (b) prefabricated component.

Different from the traditional steel-concrete composite bridge, the UHPC panel is fabricated to connect the double I-shaped steel girders in the prefabricated factory. As a result, the fully prefabricated component can be transported and lifted integrally. The main advantages of the component are as 
follows: (1) the fully precast scheme can significantly decrease on-site construction time; (2) the shear pockets, as well as the pocket-induced problems, such as construction complexity, longer construction time, and higher requirement for fine construction, can be eliminated; (3) the manufacturing quality of the prefabricated components can be guaranteed.

Figure 2 shows the typical bending moment envelops of a continuous beam bridge. It is seen that the negative bending moment of the main beam reaches the maximum value at the top of the pier, and gradually decreases from the peak region to the two sides. Owing to the high tensile strength of UHPC, it may be considered to cast UHPC on-site in the negative bending moment area near to the support. Note that the interfacial strength between the poured UHPC and the prefabricated part is weak due to the discontinuity of the steel fiber, the weak interfaces are thus set in the areas with relatively lower negative bending moment. As shown in the right side of Figure 2, the T-shaped UHPC joint in the negative bending moment area is proposed to significantly decrease the interfacial cracking risk during the service life. It has a lengthened top that looks like the letter " $\mathrm{T}$ " from the side view; thus, it was named a "T-shaped joint". Besides, the prestressed system commonly used in the negative bending moment area can be avoided, which greatly speeds up the on-site construction time.

To validate the effectiveness of the proposed design, a comparative study on the model tests between the T-shaped joint and the traditional girder-to-girder joint (herein referred to as "I-shaped joint") was conducted as follows.

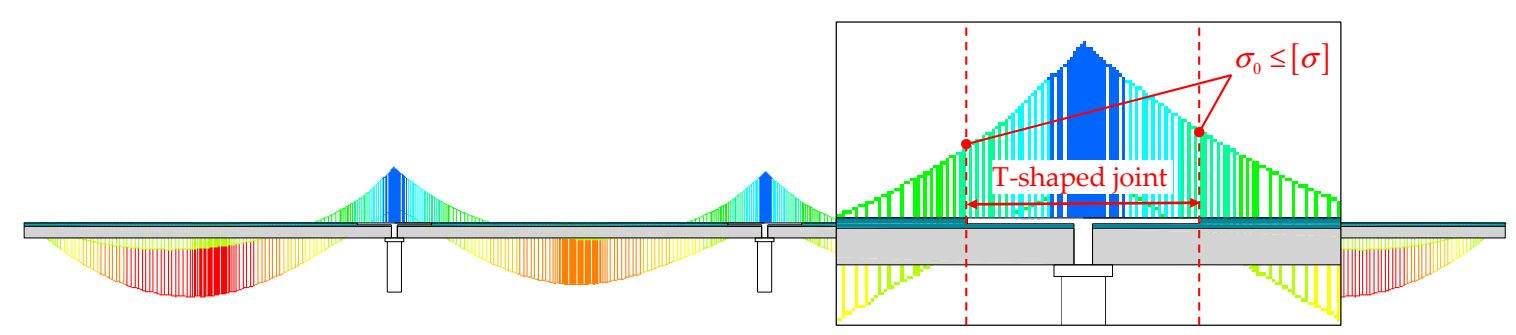

Figure 2. Bending moment envelops of common continuous beam bridge.

\section{Comparative Model Test: The First Generation T-Shaped Joint and the Traditional I-shaped Joint}

\subsection{Experimental Model}

As shown in Figure 3a, the specimen is $6.2 \mathrm{~m}$ long and $1.875 \mathrm{~m}$ wide, composed of two joints and three prefabricated steel-UHPC composite girder elements, termed as part A, part B, and part C. The T-shaped joint is employed to connect two prefabricated components of part $\mathrm{B}$ and part $\mathrm{C}$, and the other one is the traditional I-shaped joint (from the side view, the joint is shaped like the letter "I") connecting part $\mathrm{A}$ and part $\mathrm{B}$.

Part A, part B, and part $C$ are the so-called prefabricated components. The pre-cast UHPC panel is reinforced by $16 \mathrm{~mm}$ diameter longitudinal steel bars with a central spacing of $83.4 \mathrm{~mm}$, and reduced to $41.7 \mathrm{~mm}$ in the post-cast joint parts. In the transverse direction, the steel bar is $8 \mathrm{~mm}$ in diameter, with spacing of $100 \mathrm{~mm}$. The reinforcement layout is displayed in Figure $3 \mathrm{~b}$. The steel girders of the specimen were fabricated by Q235 (the steel with yield strength of $235 \mathrm{MPa}$ ). 


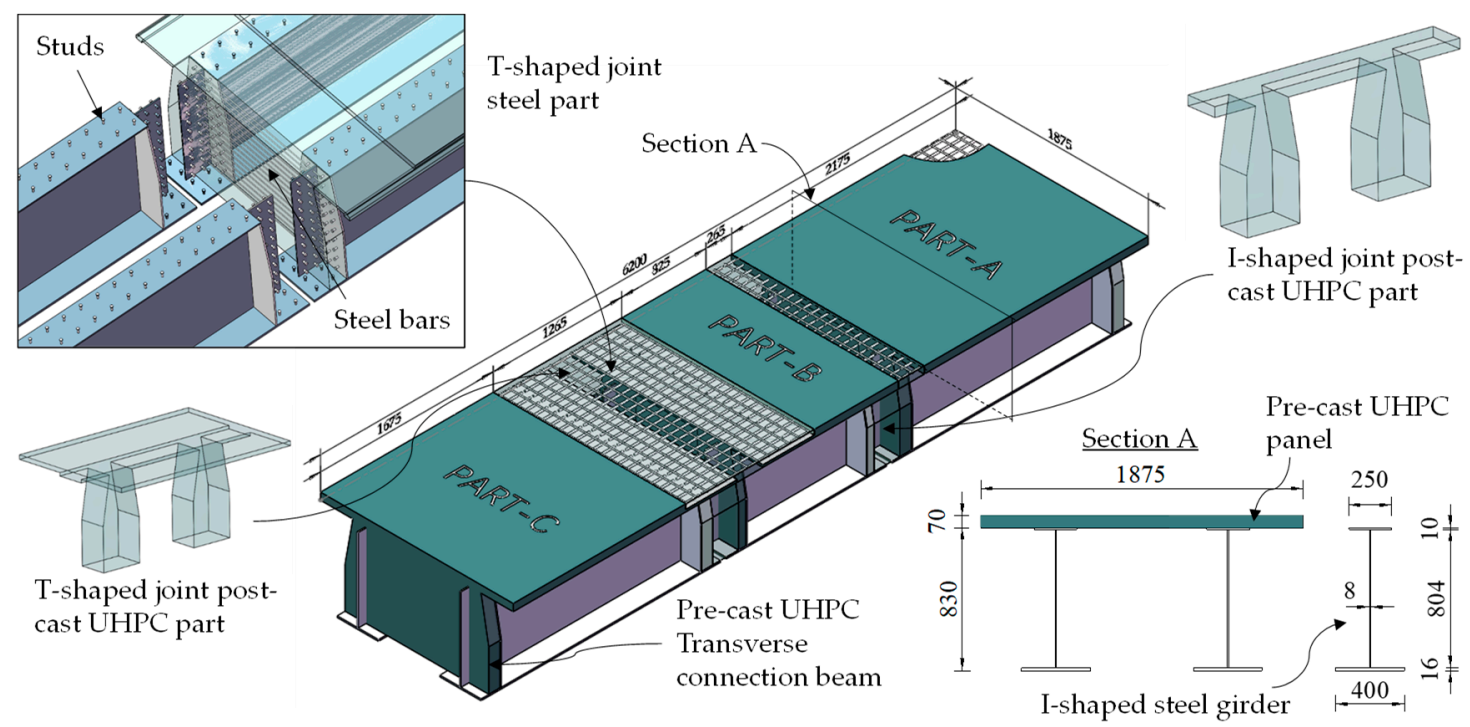

(a)

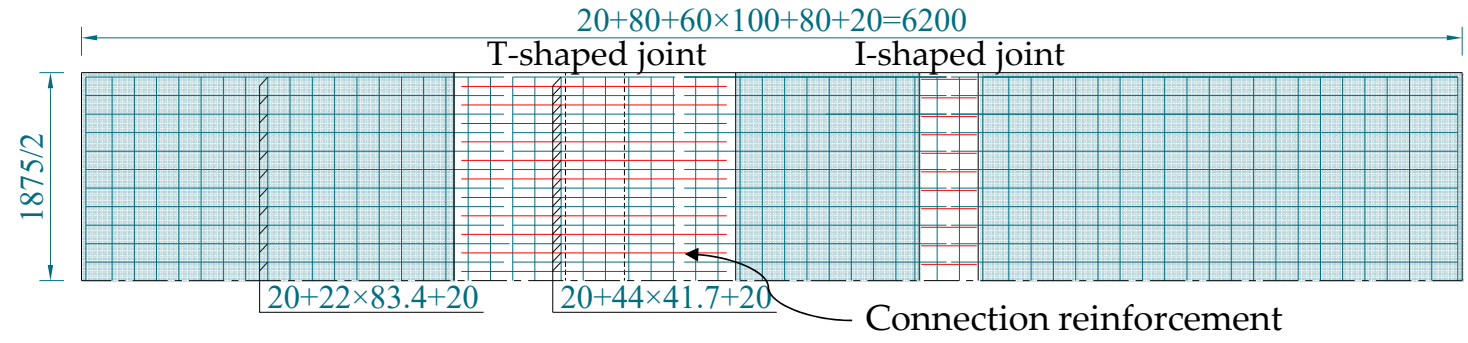

(b)

Figure 3. Illustration of the comparative model test (units: mm): (a) specimen display; (b) reinforcement layout.

In reference to Shao [19], under natural curing conditions, the curing time-dependent shrinkage strain is in the range of 200-900 $\mu \varepsilon$ [1,20-22], while under the steam curing conditions, the temperature-dependent shrinkage strain is generally in the range of 622-900 $\mu \varepsilon$, and the strain will reduce to zero after curing $[1,23,24]$. Consequently, the shrinkage-induced cracking is easy developed in the interface between the prefabricated UHPC and the newly cast UHPC. To verify the effect of shrinkage on the cracking development, the shrinkage test was conducted on part A (natural curing) and part $C$ (steam curing) with the same reinforcement ratio and joint width.

The main fabrication process is shown in Figure 4: (1) fabricating the I-shaped steel girders; (2) deploying the steel bars in pre-cast parts (part A (PA), part B (PB), and part C (PC)); (3) casting UHPC for prefabricated components; (4) steam curing of part B and part C; (5) deploying the steel bars in post-cast joint parts (T- and I-shaped joints); (6) casting UHPC for the joint parts; (7) natural curing of part A and joint parts; and (8) completing the experimental model. It is worth noting that the process is identical to the actual construction sequence. 


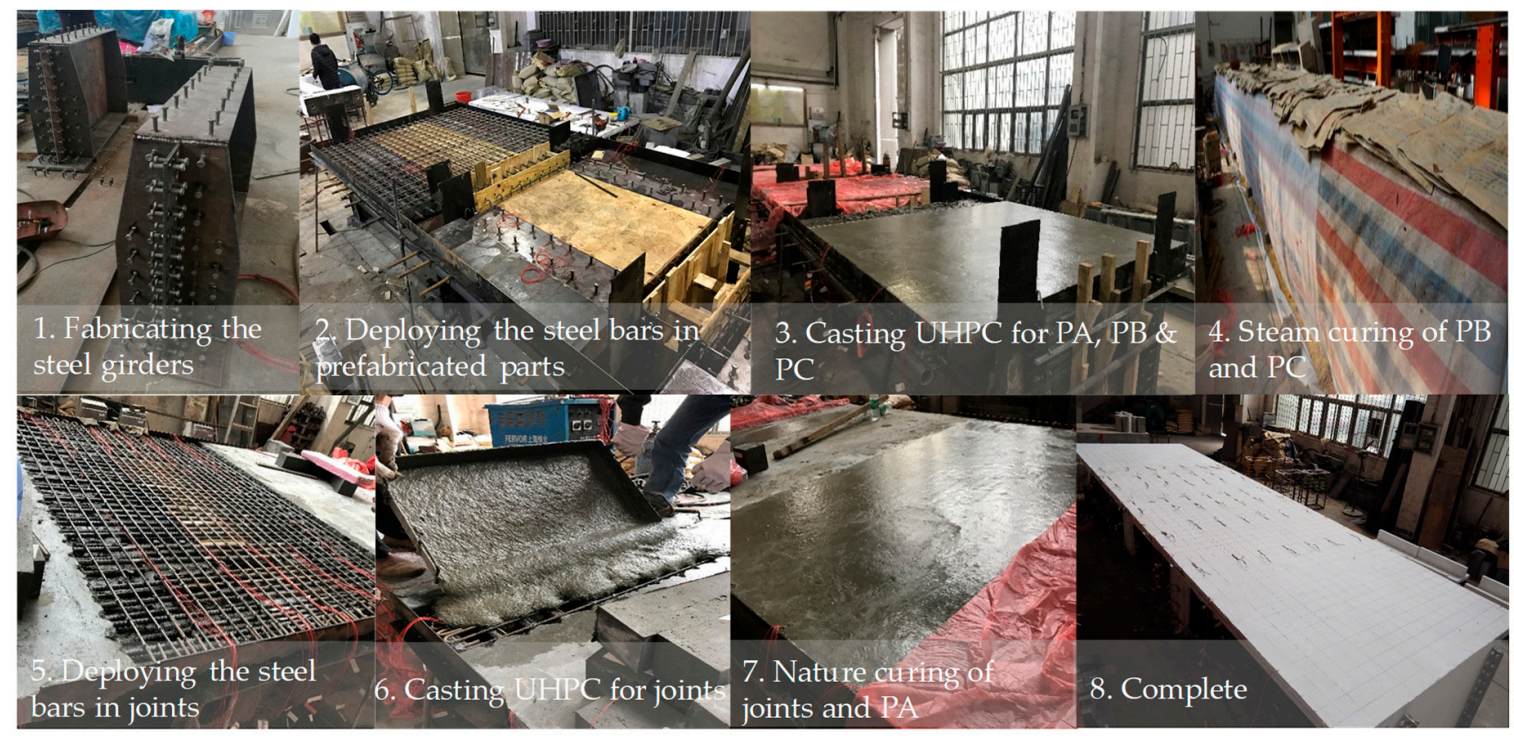

Figure 4. Specimen fabrication process. PA: part A, PB: part B, PC: part C.

The composition of the UHPC material was the same as that in reference [25] (Table 1). Two types of steel fibers were employed in the UHPC material, one was $\Phi 0.2 \times 13 \mathrm{~mm}$ straight fibers and the other was $\Phi 0.3 \times 25 \mathrm{~mm}$ with hook-ends. The content within and beyond the joint region were slightly different (as shown in Table 2). The mechanical properties, including compressive strength, flexural strength, and elastic modulus of UHPC, were tested by following the standard methods of MOHURD (Ministry of Housing and Urban-Rural Development) [26]. Six specimens are conducted for each test, and the average values are listed in Table 2.

Table 1. UHPC Martials Proportion (in reference [25]).

\begin{tabular}{cc}
\hline Material & Mass Ratio \\
\hline Cement (PO42.5) & 0.7 \\
Silica fume & 0.2 \\
Fly ash & 0.1 \\
Quartz sand & 1.1 \\
Quartz powder & 0.1 \\
Slag powder & 0.2 \\
Superplasticizer & 0.015 \\
Water & 0.2 \\
Steel fiber (volume ratio $(\%))$ & $2.0 / 2.5$ \\
\hline
\end{tabular}

Table 2. Mechanical properties of UHPC.

\begin{tabular}{cccccc}
\hline $\begin{array}{c}\text { Curing } \\
\text { Condition }\end{array}$ & $\begin{array}{c}\text { Parts of the } \\
\text { Specimen }\end{array}$ & $\begin{array}{c}\text { Fiber Type } \\
(\mathbf{d} \times \mathbf{l f}, \mathbf{V f})\end{array}$ & $\begin{array}{c}\text { Compressive } \\
\text { Strength } \mathbf{( M P a )}\end{array}$ & $\begin{array}{c}\text { Flexural } \\
\text { Strength (MPa) }\end{array}$ & $\begin{array}{c}\text { Young's } \\
\text { Modulus (GPA) }\end{array}$ \\
\hline Steam & Part B and C & $0.2 \times 13 \mathrm{~mm}, 1 \%+$ & 139.6 & 23.7 & 42.7 \\
Natural & Part A & $0.3 \times 25 \mathrm{~mm}, 1 \%$ & 137.1 & 25.3 & 42.5 \\
Natural & Two joint parts & $0.2 \times 13 \mathrm{~mm}, 1 \%+$ & 140.7 & 26.4 & 43.9 \\
& & $0.3 \times 25 \mathrm{~mm}, 1.5 \%$ & & & \\
\hline
\end{tabular}

For the loading convenience of the experimental test, the specimen was inversely configured to produce a negative bending moment. The specimen was simply supported on the bottom supports, as shown in Figure 5a. In order to ensure that the two joints were under the same load, the specimen was loaded in the form of four-point bending, the hydraulic MTS (Testing systems, Mechanical testing, and Sensing solutions) actuator was employed to apply the loading to the model. Before loading, 
a careful visual inspection on the UHPC panel indicated that there were no visible shrinkage-induced cracks, and thus the natural curing scheme of the joint was considered to be feasible. During the test, the deflection of the mid-span and the crack development of the UHPC panel were recorded step-by-step. The configuration of the measurement points and the distribution of the dial gauges and dial indicator are shown in Figure $5 b$.

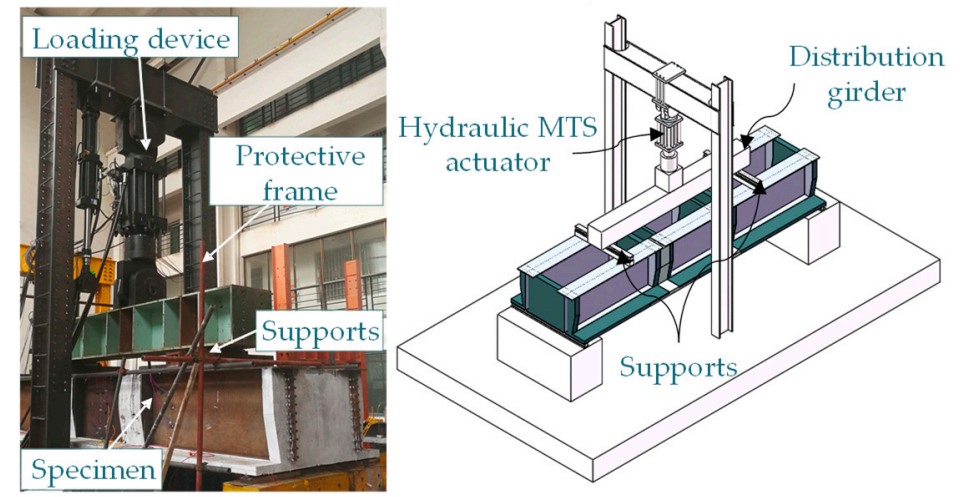

(a)

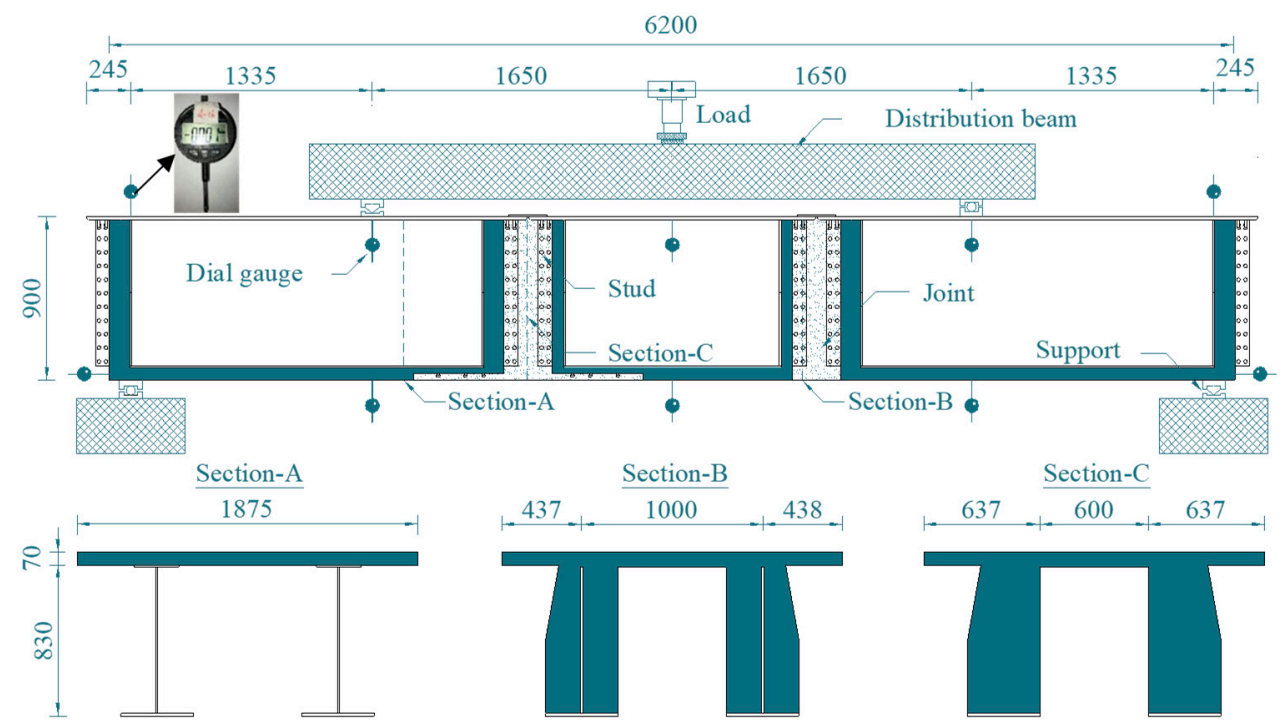

(b)

Figure 5. Loading and measuring device: (a) Loading method; (b) measuring device layout.

\subsection{Test Results}

\subsubsection{Load-Deflection Curve and Crack Development}

As shown in Figure 6a, the loading process can be divided into three stages:

i. Elastic stage. During this stage, the UHPC panel does not show any cracks, and the specimen exhibits no stiffness reduction. When the applied load reaches $605 \mathrm{kN}$, the curve deflects slightly, indicating that the stiffness of the specimen decreases slightly, and a crack with a width of $0.02 \mathrm{~mm}$ is found at the joint interface.

ii. Crack propagation stage. After $605 \mathrm{kN}$, the short cracks develop into long cracks, and the width gradually increases in the joint interface. Therefore, this stage is defined as the crack propagation stage.

iii. Yield stage. When the applied load reaches $2190 \mathrm{kN}$, the load-deflection curve deflects obviously, indicating that the stiffness of the specimen decreases significantly. Subsequently, the structural 
deformation increases rapidly, but the load cannot increase anymore. Thus, this stage is defined as the yield stage.

During the loading process, the cracks can only be found at the interface of the two joints, and no visible cracks develop in the rest of the parts. The crack development curve is displayed in Figure $6 \mathrm{~b}$, where the " $\mathrm{T}$ " and " $\mathrm{I}$ " denote T-shaped joint and I-shaped joint, respectively, and the " $\mathrm{L}$ " and " $\mathrm{R}$ " indicate the left and right side, respectively. It is seen that the cracks develop at four interfaces with similar trend, and the crack on the right side of the I-shaped joint grows slightly faster than that of the left side.

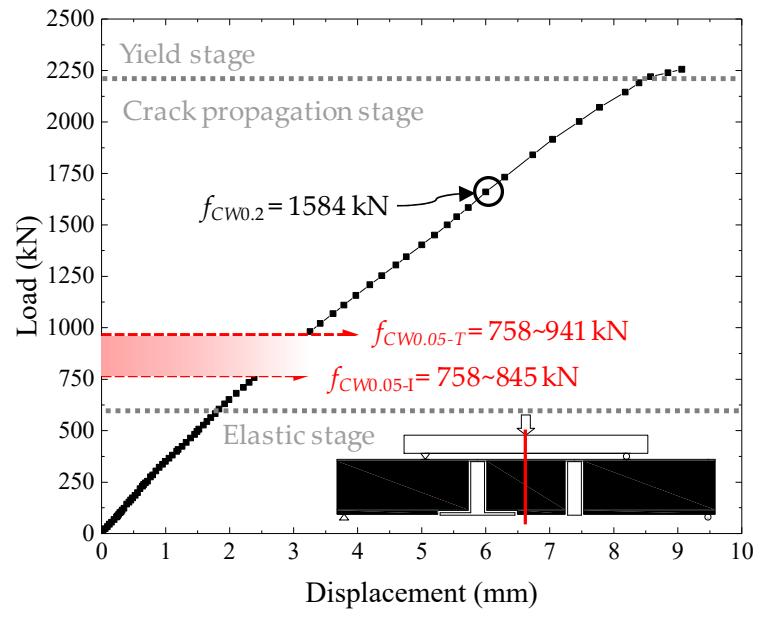

(a)

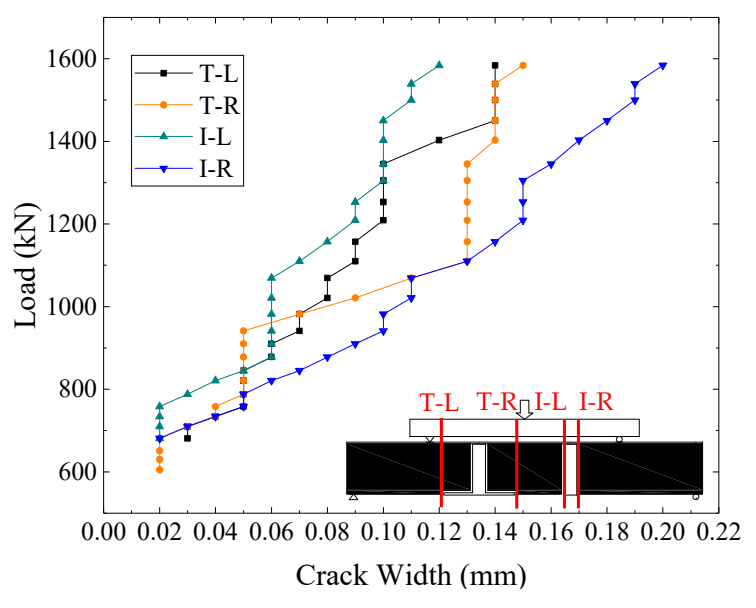

(b)

Figure 6. Test results of comparative model test: (a) load-deflection curve in mid-span; (b) load-crack width curve of joint interface. T: T-shaped joint, I; I-shaped joint, L: left side, R: right side.

\subsubsection{Nominal Cracking Stress}

According to Rafiee [27], when the maximum crack width of UHPC does not exceed $0.05 \mathrm{~mm}$, the crack has no influence on the durability of UHPC. In addition, the cracks are difficult to observe with the naked eye in practical engineering when the maximum crack width is smaller than $0.05 \mathrm{~mm}$ [28]. Thus, the allowable crack width is defined as $0.05 \mathrm{~mm}$ for the steel-UHPC composite specimen, and the corresponding load can be called the cracking load. Thereby, the nominal cracking stress in UHPC is attained by using a representative load, which causes a maximum crack width of $0.05 \mathrm{~mm}$ in UHPC.

Luo et al. [29,30] conducted negative bending tests on 40 steel-UHPC composite specimens. It was found that when the maximum crack width reaches $0.05 \mathrm{~mm}$ in UHPC, the specimens are still at the early phase of the crack propagation. When the applied load reaches $76.7-86 \%$ of the ultimate load, the strain distribution along with the height of the section still roughly conforms to the plane section assumption. Consequently, the nominal cracking stress could be calculated based on the linear elastic assumption rather than any nonlinearity consideration.

The nominal cracking stress can be calculated by $\sigma=M_{d} y / \alpha_{E} I$, where $M_{d}$ denotes the applied moment without considering moment redistribution, $y$ denotes the distance from the neutral axis to the UHPC panel surface, $E=E_{s} / E_{U H P C}$, and $I$ denotes the second-moment area of conversion of composite section. The applied load and the nominal cracking stress of the critical sections (Figure $5 b$ ) are listed in Table 3. $P_{c r}$ is the nominal cracking load, and it is defined as the maximum load level when the crack width approaches $0.05 \mathrm{~mm}$. Considering that the crack width in the mid-span and UHPC matrix was extremely small during the whole process, the yield value of $2190 \mathrm{kN}$ was applied within the nominal stress calculation.

As shown in Table 3, when the crack width reaches $0.05 \mathrm{~mm}$, the nominal stress of the T-shaped joint interface is in the range of $4.42-5.48 \mathrm{MPa}$, and the mean value is $4.96 \mathrm{MPa}$; whereas for the I-shaped 
joint, the corresponding value varies from 3.21 to $3.57 \mathrm{MPa}$, and the mean value is $3.39 \mathrm{MPa}$. Thus, compared to the I-shaped joint, the T-shaped joint exhibits more reliable crack resistance performance. Furthermore, the interfaces of the T-shaped joint can be adjusted to be far from the peak point of the negative bending moment zone, and the tensile crack of the interface can be completely avoided in theory.

Table 3. Durability-based nominal stress of critical sections.

\begin{tabular}{ccccc}
\hline Section Item & $\mathbf{P}_{\mathbf{c r}} / \mathbf{k N}$ & $\mathbf{M}_{\mathbf{c r}} / \mathbf{k N} \cdot \mathbf{m}$ & $\boldsymbol{\sigma}_{\mathbf{c r}} / \mathbf{M P a}$ & Section No. \\
\hline T-shaped joint left interface & 941 & 638 & 5.48 & Section A \\
T-shaped joint right interface & 845 & 564 & 4.42 & Section A \\
I-shaped joint left interface & 845 & 564 & 3.57 & Section B \\
I-shaped joint right interface & 788 & 526 & 3.21 & Section B \\
Mid-span of the specimen & 2190 & 1462 & 12.88 & Section C \\
UHPC matrix (part A) & 2190 & 1462 & 12.77 & Section A \\
\hline
\end{tabular}

\subsubsection{Shrinkage in UHPC}

The shrinkage strain of the UHPC panel was obtained by embedded gauges. The test lasted for $2112 \mathrm{~h}$ (88 days, from March to June), the temperature was in the range of $10.5-26.5^{\circ} \mathrm{C}$. Part A adopted natural curing, and the test condition was the same as the actual construction site. While Part $\mathrm{C}$ adopted steam curing, the curing lasted for $48 \mathrm{~h}$ with a temperature of $98^{\circ} \mathrm{C}$. After $48 \mathrm{~h}$, the specimen was exposed to the environment when the temperature decrease to normal. The strains were recorded every $2 \mathrm{~h}$ during the steam curing period and changed to every $24 \mathrm{~h}$ in the first month, then every $48 \mathrm{~h}$ in the second month. The test results are shown in Figure 7.

As can be seen in the figure, for the natural curing part (Figure 7a), the shrinkage increased rapidly in the first $250 \mathrm{~h}$, then fluctuated until the end of the test. The strain was in the range of 87-173 $\mu \varepsilon$, and the average value was $121 \mu \varepsilon$. While for the steam curing part (Figure $7 \mathrm{~b}$ ), the strain increased rapidly during the curing period $(48 \mathrm{~h})$, then showed a slight decrease; the maximum value was $164 \mu \varepsilon$. Also, $2000 \mathrm{~h}$ (83.3 days) later, the shrinkage strain was in the range of 30-76 $\mu \varepsilon$. The maximum shrinkage strain of the reinforced UHPC deck was $173 \mu \varepsilon$ under natural curing, and was $164 \mu \varepsilon$ under steam curing. Compared to past research [1,20-25], it is seen that the reinforcement has a significant effect on UHPC material shrinkage.

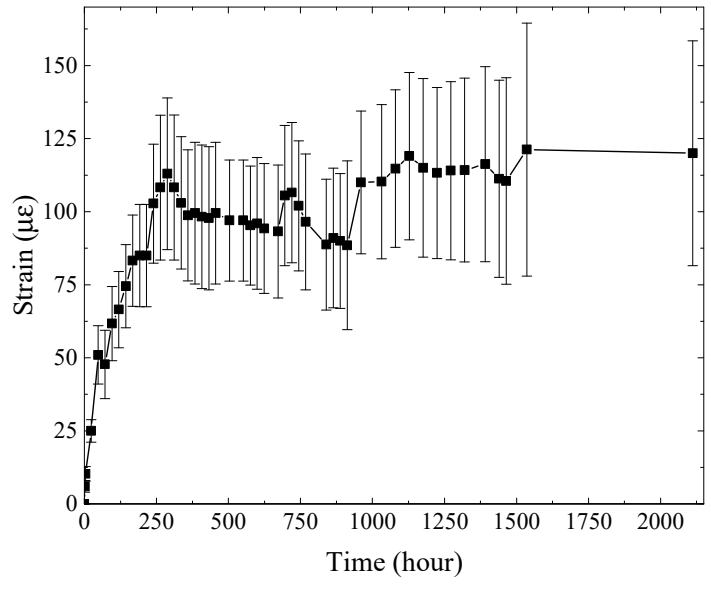

(a)

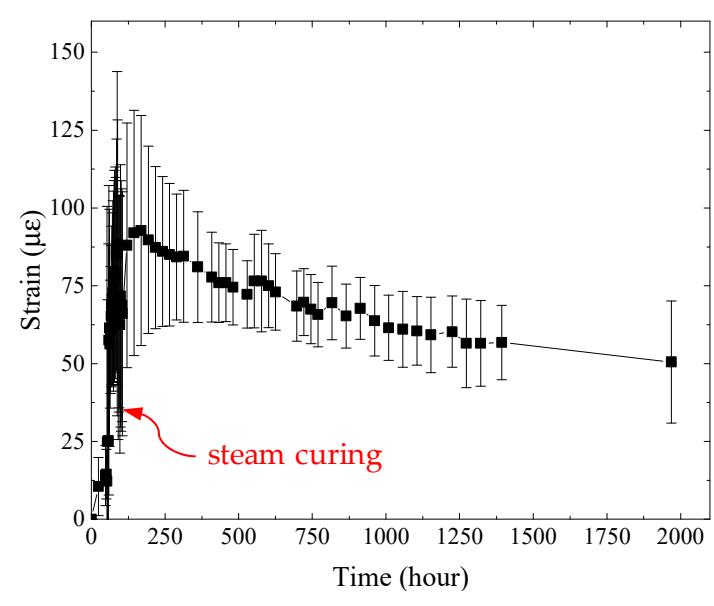

(b)

Figure 7. Shrinkage test results: (a) shrinkage strain of natural curing part A; (b) shrinkage strain of steam curing part $C$. 


\subsection{Discussion}

Compared to the conventional I-shaped joint, the proposed T-shaped joint exhibited a slight improvement in terms of crack resistance performance (i.e., the mean value of the two schemes were $4.96 \mathrm{MPa}$ and $3.39 \mathrm{MPa}$, respectively). Moreover, the weak interface of the T-shaped joint was set to be far from the peak region of the negative bending moment, which dramatically reduced the cracking risk.

Note that in general, the crack is developed at the joint interface, and there was no visible crack generated at the UHPC matrix and the joint center (corresponding to the pier top position). This phenomenon demonstrates that the joint interface is the key issue of the design.

The shrinkage test indicated that the maximum shrinkage strain of the steam curing part and the natural curing part was $173 \mu \varepsilon$ and $164 \mu \varepsilon$, respectively. In reference to the UHPC axial tensile test in [31], the cracking strains of plain UHPC with different fiber content $(2-3.5 \%)$ were in the range of 192-198 $\mu \varepsilon$. Therefore, for plain UHPC without reinforcement, shrinkage-induced cracking was easily developed at the successively poured UHPC interface. In the present test, before loading, no visible crack was found in the UHPC panel due to the introduction of steel bars. Note that in the first generation T-shaped joint design, there was no reinforcement between the UHPC transverse beam and the post-cast T-shaped joint (Figure 8a), which may lead to shrinkage cracks in the lower part. Besides, the rough surface quality of the UHPC transverse beam is uncontrollable, and it has a great influence on the joint strength. Consequently, we replaced the UHPC transverse beam with a steel diaphragm, and two steel stiffeners were added to each girder (Figure 8b). The optimized scheme was named as the second generation T-shaped joint.

The second generation T-shaped joint can further reduce the weight of the prefabricated composite component. The steel diaphragm can also be employed as the formwork for casting UHPC, which speeds up the on-site construction time. The following section validates the effectiveness of the optimized scheme through a scaled model test, and the design and calculation method are also presented.

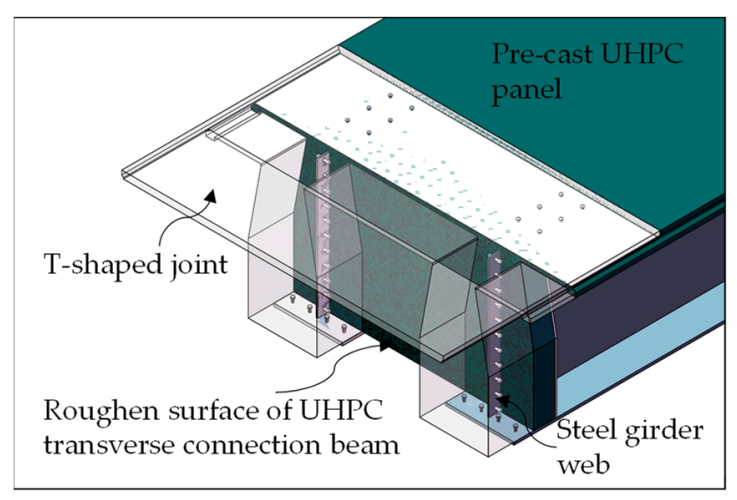

(a)

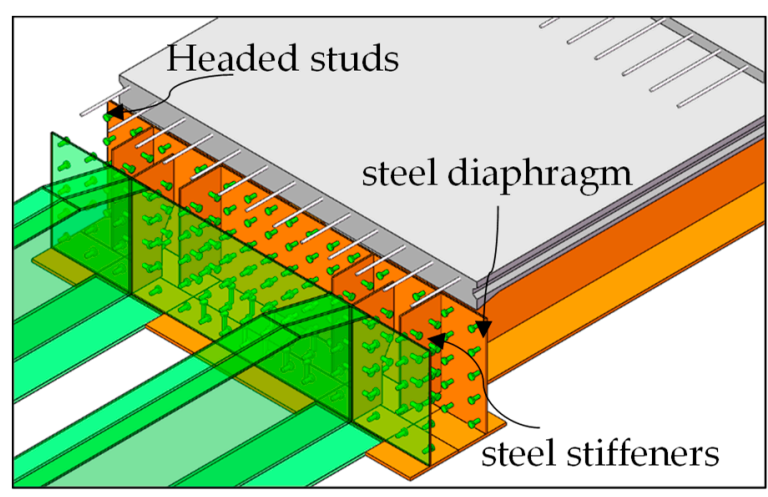

(b)

Figure 8. The design schematic of two T-shaped joints: (a) the first generation T-shaped joint; (b) the second generation T-shaped joint.

\section{Experimental Test of the Second Generation T-Shaped Joint}

\subsection{Experimental Model}

As shown in Figure 9, the specimen was $6.4 \mathrm{~m}$ in length and $0.7 \mathrm{~m}$ in width, and was composed of one T-shaped joint part and two steel-UHPC composite girder parts. In the longitudinal direction, the panel was reinforced by $16 \mathrm{~mm}$ diameter steel bars with a central spacing of $107.3 \mathrm{~mm}$, and reduced to $53.7 \mathrm{~mm}$ in the joint parts. In the transverse direction, the steel bar was $12 \mathrm{~mm}$ in diameter with a spacing of $100 \mathrm{~mm}$. 


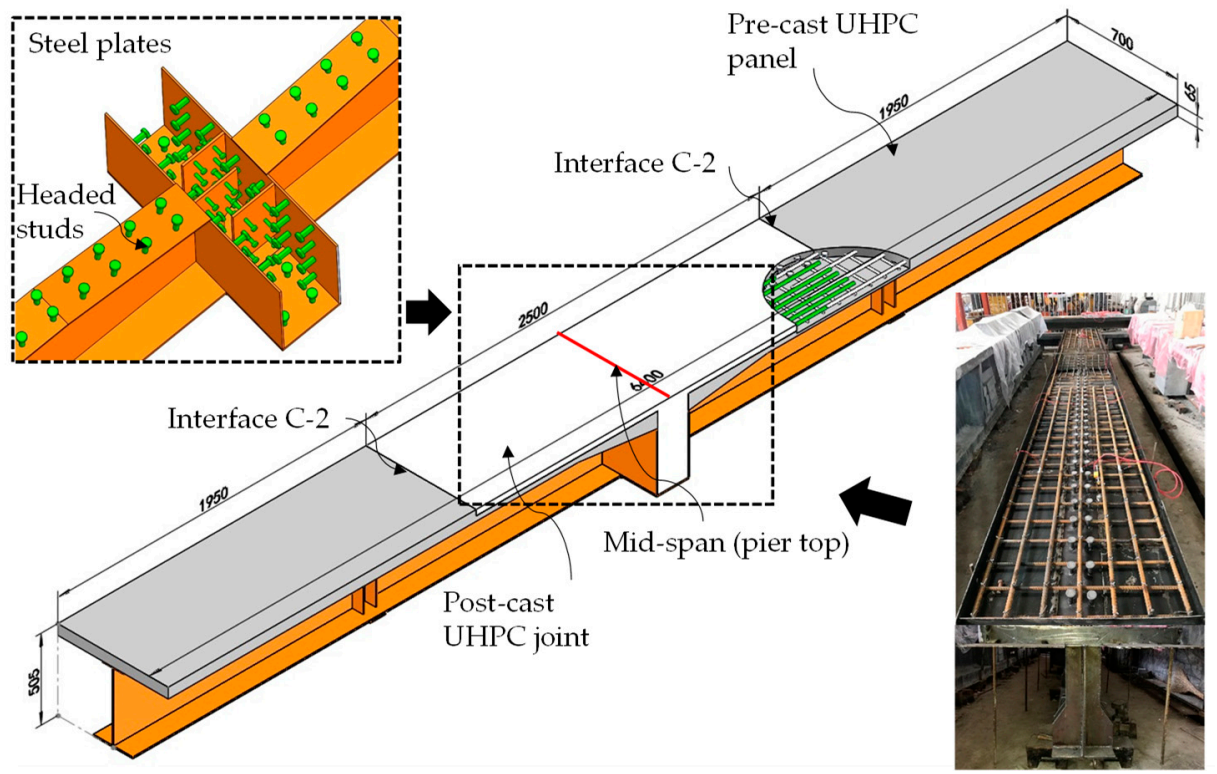

Figure 9. Diagram of the second generation T-shaped joint model test specimen.

The main fabrication processes was identical to the comparative model test: (1) I-shaped steel girder fabrication; (2) installing the formwork used for pouring concrete, deploying the steel bars of pre-cast parts; (3) casting the pre-cast UHPC and roughening the surface; (4) curing the pre-cast UHPC parts with steam; (5) deploying the steel bars of post-cast T-shaped joint and treating with natural curing.

The mechanics of the UHPC material are listed in Table 4. The loading and measuring schematic was the same as the comparative model test (Figure 10).

Table 4. Mechanical properties of UHPC (MPa).

\begin{tabular}{ccccc}
\hline Part Item & Curing Condition & Compressive Strength & Flexural Strength & Young's Modulus \\
\hline Prefabricated part & Steam curing & 162.38 & 28.74 & 49,030 \\
Post-cast Joint part & Natural curing & 135.01 & 32.19 & 45,820 \\
\hline
\end{tabular}

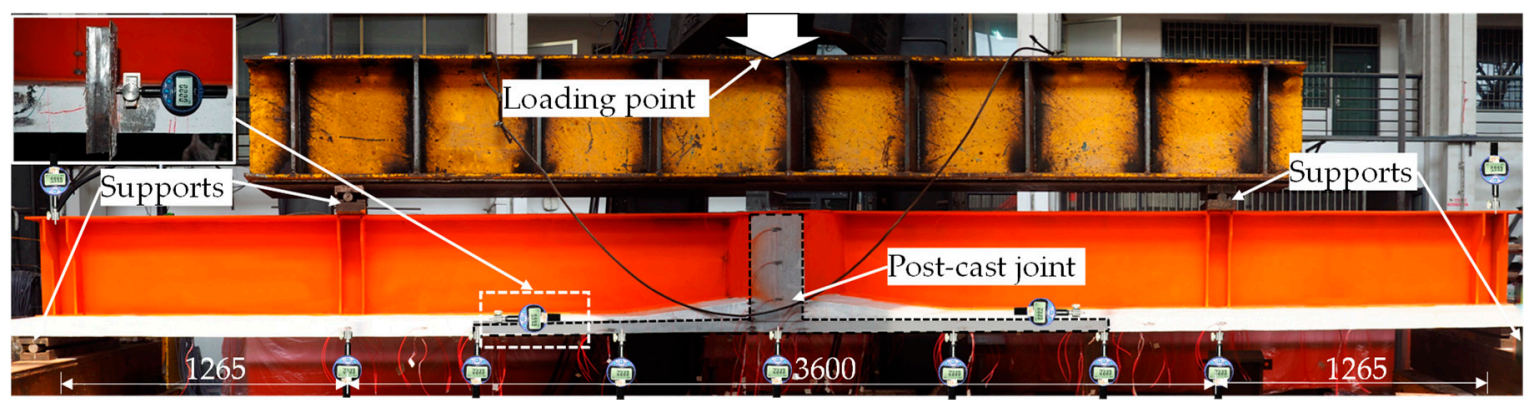

Figure 10. Loading and measuring device.

\subsection{Test Results}

\subsubsection{Load-Deflection Curve and Crack Development}

As shown in Figure 11a, the loading process can be divided into the same three stages: (1) elastic stage, (2) crack propagation stage, and (3) yield stage. The elastic stage is defined as an applied load less than $400 \mathrm{kN}$; a crack could be found in the joint interface. The crack propagation stage refers to an applied load less than $950 \mathrm{kN}$; the small and dense cracks propagated in the specimen, and the main crack (the crack which was larger and developed faster than the rest) gradually appeared at the joint 
interface. Furthermore, the stiffness of the specimen decreased slightly. The specimen develops to the yield stage when the applied load exceeds $950 \mathrm{kN}$; the deflection increased rapidly and the stiffness of the specimen decreased significantly—simultaneously, the width of the main crack increased drastically. At $1033.9 \mathrm{kN}$, the I-shaped steel girder bucked close to the loading point and the test terminated.

The main crack development is shown in the Figure 11b. When the crack (main crack, Interface C-1 and C-2 in Figure 11b) width reached $0.05 \mathrm{~mm}$, the applied load was in the range of 143.5-196.6 kN; while for the prefabricated parts, the range was $336.5-424.5 \mathrm{kN}$. The cracks were found below the loading point, and the crack in the mid-span was extremely small $(\leq 0.05 \mathrm{~mm})$ during the entire loading process.

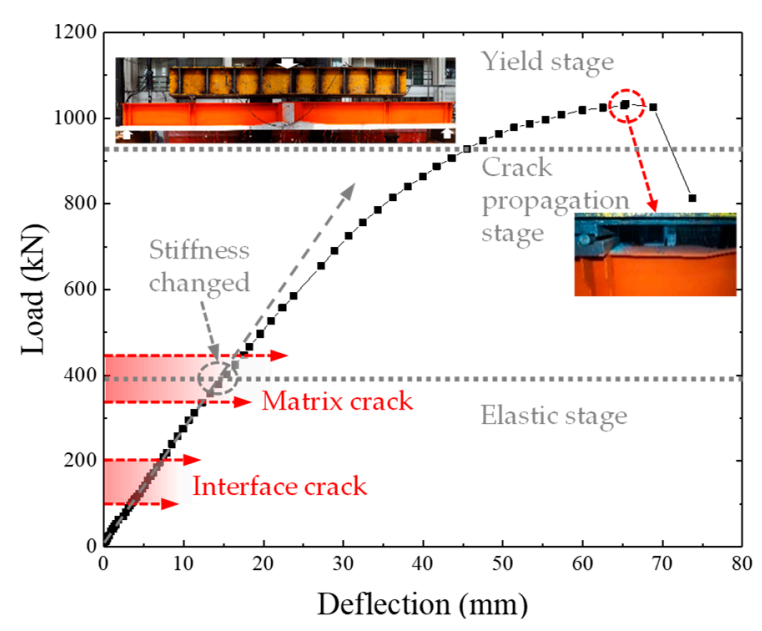

(a)

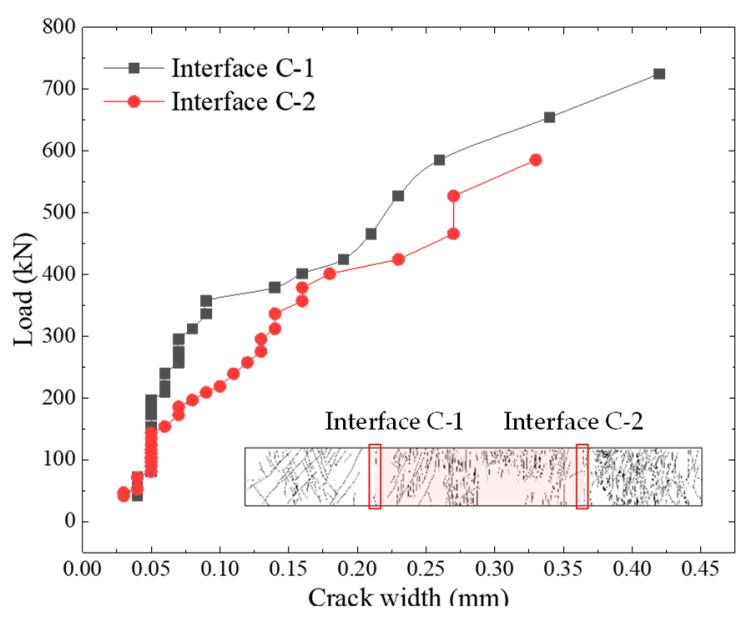

(b)

Figure 11. Test results: (a) load-deflection of mid-span; (b) load-crack width curve of joint interface.

\subsubsection{Nominal Cracking Stress}

The nominal strength calculation method was identical to the comparative scheme. Considering that the crack width in the mid-span was extremely small, the yield value $(1033.9 \mathrm{kN})$ was employed. The calculation results are listed in Table 5. The calculation sections are depicted in Figure 12.

Table 5. Durability nominal stress of critical sections.

\begin{tabular}{cccc}
\hline Section Item & $\mathbf{P}_{\mathbf{c r}} / \mathbf{k N}$ & $\mathbf{M}_{\mathbf{c r}} / \mathbf{k N} \cdot \mathbf{m}$ & $\boldsymbol{\sigma}_{\mathbf{c r}} / \mathbf{M P a}$ \\
\hline Section 2 (interface) & 196.6 & 124.3 & 7.39 \\
Section 4 (interface) & 143.5 & 90.8 & 5.40 \\
Section 1 (matrix) & 424.5 & 268.5 & 15.96 \\
Section 5 (matrix) & 336.5 & 212.8 & 12.66 \\
Section 3 (mid-span, pier top) & 1033.9 & 653.9 & 19.02 \\
\hline
\end{tabular}

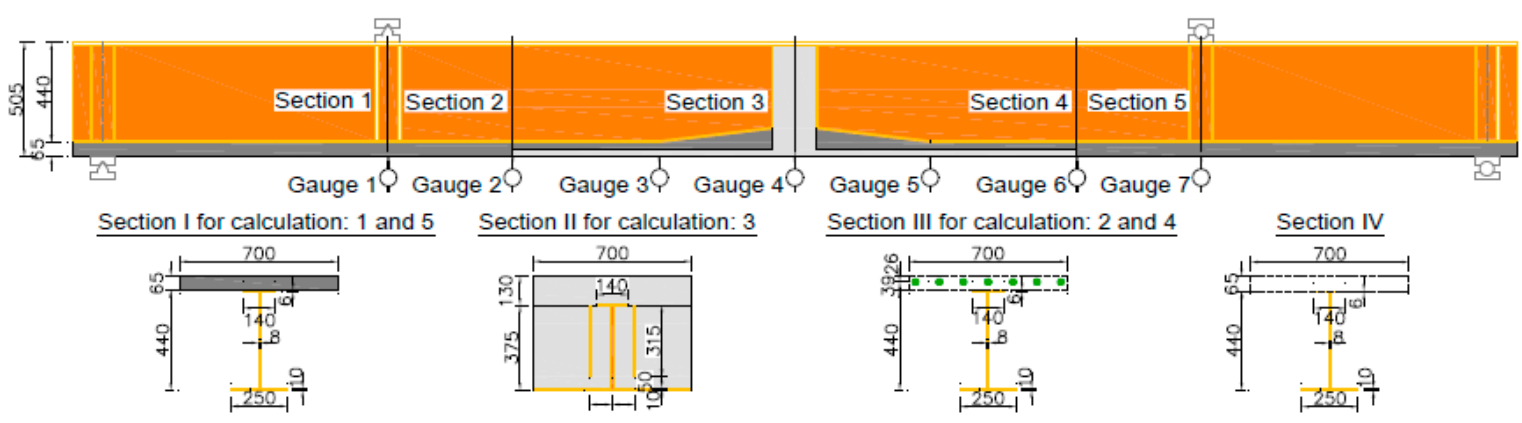

Figure 12. Gauge and calculation sections layout. 
As shown in Table 5, when the crack width reaches $0.05 \mathrm{~mm}$, the nominal stress of the T-shaped joint interface is in the range of 5.40-7.39 MPa, and the mean value is $6.4 \mathrm{MPa}$. Compared to the first generation T-shaped joint, even though the reinforcement ratio is slightly lower (i.e., the second scheme is $3.09 \%$, the original is $3.37 \%$ ), the nominal strength is higher (the original is $4.96 \mathrm{MPa}$ ). Furthermore, the strength of the joint center is significantly improved (148\%). Combined with the construction advantages, the second generation T-shaped joint optimizes the original scheme significantly. However, as per the original design, the joint interface strength is still the key issue of the design.

In previous research, Pan [32] proposed five types of UHPC joints suitable for the prefabricated composite deck system. Axial tensile tests on UHPC panels and flexural tests on steel-UHPC composite girders were conducted. The reinforcement ratio was in the range of 3.84-10.54\%, and the shape of the joint included: conventional wet joint, irregular joint shape, and steel plate-enhanced joint. The durability-based tensile strength varied from 7.9 to $15.7 \mathrm{MPa}$ for axial tensile tests, and 8.9 to 14.2 MPa for flexural tests. Chen [33] conducted two flexural tests on nine types of UHPC joints suitable for the lightweight steel-UHPC composite deck system. The reinforcement ratio was $4.52-7.92 \%$, and the joint type included: dense reinforcement enhanced joint, steel plate enhanced joint, and welded reinforcement enhanced joint. The test results showed that the durability-based tensile strength was 11.0-26.5 MPa. Additionally, the joint allowable strength was significantly increased with the increasing of the reinforcement ratio.

According to the test results in the above literature, it can be seen that the following methods can increase the joint strength significantly: (1) increasing the reinforcement ratio at the interface; (2) changing the conventional joint to an irregular shape; and (3) or setting up a reinforced steel plate at the joint bottom. Meanwhile, it is worth noting that the UHPC layer in the above literature is extremely thin $(50 \mathrm{~mm})$. On the one hand, the steel fiber distribution is more favorable in a thinner UHPC slab. On the other hand, the orthotropic steel deck located at the bottom can play the role of stiffener with a thinner UHPC layer. Both of them can produce higher tensile strength. While for the joint proposed in the present study, considering the complexity of construction and economic performance, increasing the reinforcement ratio seems to be one of the most preferred solutions to improve the joint interface strength.

\subsection{Discussion}

\subsubsection{Specimen Stiffness and Deflection}

(1) Section stiffness analysis

Figure 13 displays the theoretical curvatures of sections I, II, and III (sections shown in Figure 12). The theoretical curvatures used the calculation method of ideal elasticity. It is seen that the stiffness at the joint interface was greatly reduced, and for the cracked section (Section III, ignored the tensile strength of UHPC), the theoretical value can better fit with the test result. While for the other sections, the theoretical value shows great agreement with the test value.

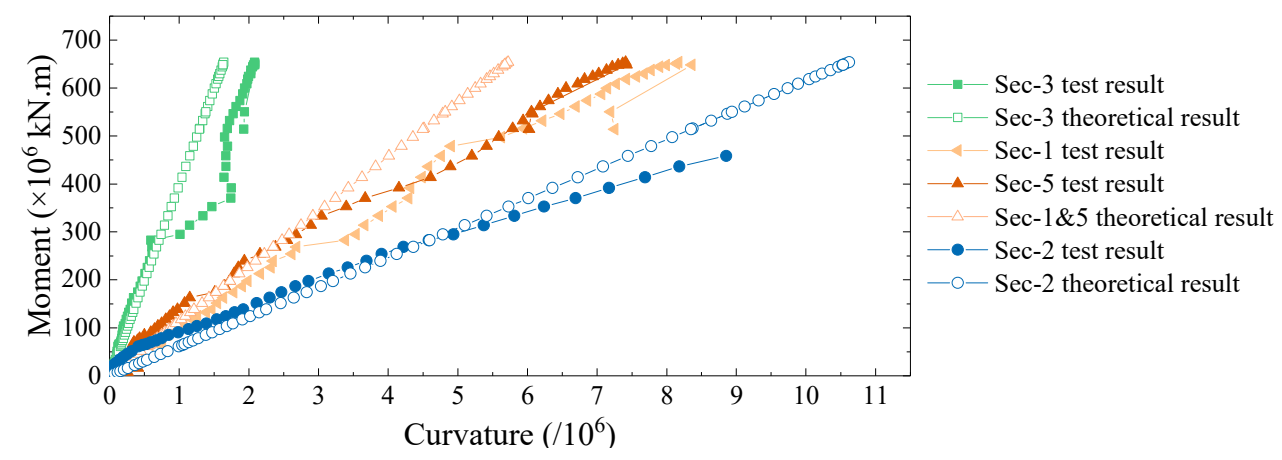

Figure 13. Moment-curvature curves of critical sections. 
(2) Analysis of specimen overall deflection

In Figure 14, the deflections of seven measurement points (the gauge 1-7 in Figure 12) were plotted with every $200 \mathrm{kN}$ and compared to the theoretical value calculated by Section III. The comparative result showed excellent agreement before $815.2 \mathrm{kN}$. When the applied load reached $1033.9 \mathrm{kN}$, the theoretical value (1033.9 $\mathrm{kN}$-theoretical-1) calculated by using Section III was a greatly underestimated experimental result; alternatively, the curve of $1033.9 \mathrm{kN}$-theoretical-2 calculated by Section IV (Figure 12, the section of I-shaped steel girder) was in good agreement with the final deflection. This indicates that when the specimen broke, the steel bars in the UHPC panel yielded, and the applied load was completely borne by the I-shaped steel girder.

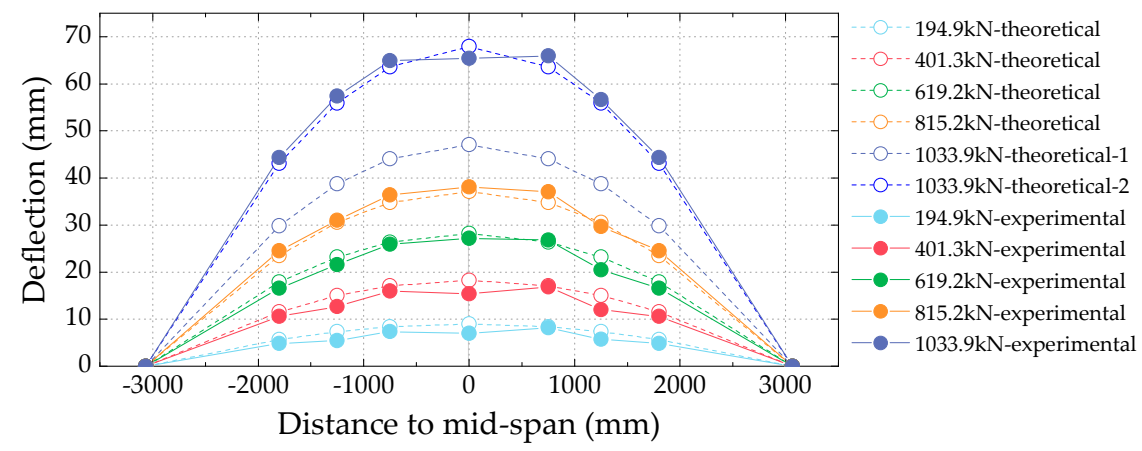

Figure 14. Comparison of analytical value and test results of specimen deflection in different load.

Consequently, when the specimen was subjected to the negative bending moment, the cracked section ignoring the UHPC tensile strength could be used to predict the theoretical deflection in the serviceability limit states. In some sense, the section of I-shaped steel girder appeared to be more reasonable for predicting the final deflection in the ultimate limit state.

\subsubsection{Crack Width Prediction}

Furthermore, there are very few crack width formulas which are applicable to steel-UHPC composite structures. Li [34] investigated the applicability of calculating flexural crack width of steel-UHPC composite deck structures using the recommended formulas in AFGC-SETRA (Association Française de Génie Civil- Service d'étude des transports, des routes et de leurs aménagement) [35] and Haibin [36]; it is observed that the results greatly differed from the measured values due to the difference of the structural characteristics. Luo et al. [30] tested 40 steel-UHPC composite plates and eight steel-UHPC composite beams. The cracking characteristics in transverse and longitudinal directions were explored, and a modified formulation based on MOHURD [37] for predicting the maximum crack width in composite (steel + UHPC) lightweight deck system was proposed as:

$$
\begin{gathered}
w_{\max }=\alpha_{c r} \psi \frac{\sigma_{s}}{E_{s}} l_{c r} \\
\alpha_{c r}=\tau_{l} \tau_{s} \beta \alpha_{c} \\
l_{c r}=1.06 c_{s}+0.152 \frac{d_{e q}}{\rho_{t e}} \\
\psi=1.1-0.12 \frac{f_{t k}}{\rho_{t e} \sigma_{s}}
\end{gathered}
$$

For a detailed discussion of the equations, one can refer to Luo et al. [30]. While it is worth noting that Luo's formula is applicable to the composite (steel + UHPC) lightweight deck system, the LWCB proposed in this paper is slightly different: 
The $\alpha_{c r}$ is the coefficient regarding loading characteristics; $\tau_{l}$ is the coefficient related to long-term effects of loads or actions, as for the UHPC matrix, Luo et al. [30] omitted it due to the extremely low shrinkage and creep of UHPC after steam curing, while for the joint interface in the present study, the recommended value $\tau_{l}=1.5$ was adopted by referring to MOHURD [37]; and $\sigma_{s}$ is the reinforcement stress. Luo et al. [30] stated that the tensile strength of UHPC should be taken into account when calculating the stress of reinforcing bar due to the bridging effect of steel fibers, while for the interface position of successively poured UHPC joints in present study, according to the stiffness analysis of the structure above, it can be seen that the cracked section can better predict the stiffness of the specimen in the serviceability limit states. Therefore, it is more reasonable to use the cracked section without taking into account the UHPC tensile strength when calculating the crack width.

Besides, the crack width of the centroid of longitudinal reinforcement $\left(w_{\max }\right)$ should be converted to the top surface $\left(w_{\text {smax }}\right)$ :

$$
w_{\text {smax }}=w_{\max } \frac{h-x}{h-x-c}
$$

where $h$ is the height of the beam; $x$ is the distance from the neutral axial of the composite beam to the top surface of UHPC deck; and $c$ is the distance from the centroid of longitudinal reinforcement to the top surface of the UHPC deck. The test value and calculation results are shown in Figure 15.

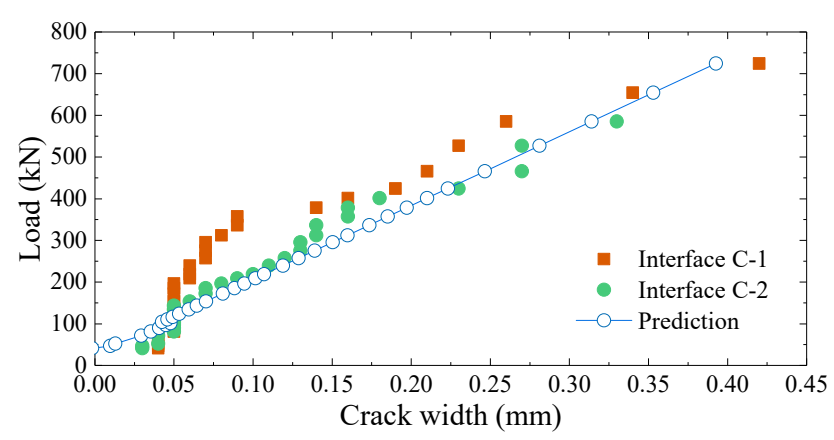

Figure 15. Prediction value and test results of joint interface crack width.

It is seen that the prediction value agrees well with the test results. While there was a small deviation at the beginning of the prediction, the reason was that the formulas ignored the tensile strength of the interface when calculating the reinforcement stress, and only took into account the section of steel bars and girders.

From Equations (1)-(5), it is observed that the crack width depends on the reinforcement stress. From the test results in the literature above [21,23], increasing the reinforcement ratio, enhancing the steel plate at the bottom of the joint, or applying the orthotropic steel bridge deck increased the reinforcement ratio in different forms, thereby reducing the reinforcement stress. Thus, the cracking strength of the joints was higher than that in the present study.

\subsubsection{Ultimate Flexural Capacity}

The analysis of the structural stiffness indicates that the steel rebars yield before the buckling of the I-shaped steel web. Thus, the calculation of the ultimate flexural capacity of the structure should consider the assumption of the yield of the steel rebar. The cracked section (Section III in Figure 9) was employed to calculate the section characteristics. Figure 16 shows the calculation diagram.

$$
M_{u, \mathrm{ULS}}=f_{c t} A_{c} y_{c 0}+f_{y} A_{r} y_{r 0}+f_{y} \frac{y_{s 0}}{y_{r 0}} A_{s 1} y_{s 1}+\frac{1}{3} f_{y} b_{s 2}\left(\frac{y_{s 0}}{y_{r 0}} y_{s 2 t}{ }^{2}+\frac{y_{0}}{y_{r 0}} y_{s 2 c}{ }^{2}\right)+f_{y} \frac{y_{0}}{y_{r 0}} A_{s 3} y_{s 3}
$$

where $f_{c t}$ denotes the tensile strength of UHPC; $A_{c}$ is the effective tensile area of UHPC deck; $y_{c 0}$ is the distance from the centroid of UHPC panel to the neutral axis of cracking section; $f_{y}$ is the yield strength of reinforcement; $A_{r}$ is the area of tensile reinforcement; $y_{r 0}$ is the distance from the centroid of 
reinforcement to the neutral axis; $y_{s 0}$ is the distance from the centroid of the I-shaped steel girder to the neutral axis of the cracked section; $A_{s 1}$ is the area of the upper flange of the I-shaped steel girder; $y_{s 1}$ is the distance from the centroid of the upper flange of the I-shaped steel girder to the neutral axis of the cracked section; $b_{s 2}$ is the thickness of the web; $y_{s 2 t}$ is the distance between the centroid of the tension part of the web and the neutral axis of the composite girder; $y_{s 2 c}$ is the distance between the centroid of the compression part of the web and the neutral axis of the composite girder; $y_{0}$ is the height from the neutral axis to the bottom of the steel girder; $A_{s 3}$ is the area of the lower flange of the I-shaped steel girder; and $y_{s 3}$ is the distance from the centroid of the lower flange of the I-shaped steel girder to the neutral axis of the cracked section.

According to Equation (6), the flexural capacity of the specimen is $650 \mathrm{kN} \cdot \mathrm{m}$, which agrees well with the test result $(654 \mathrm{kN} \cdot \mathrm{m})$.

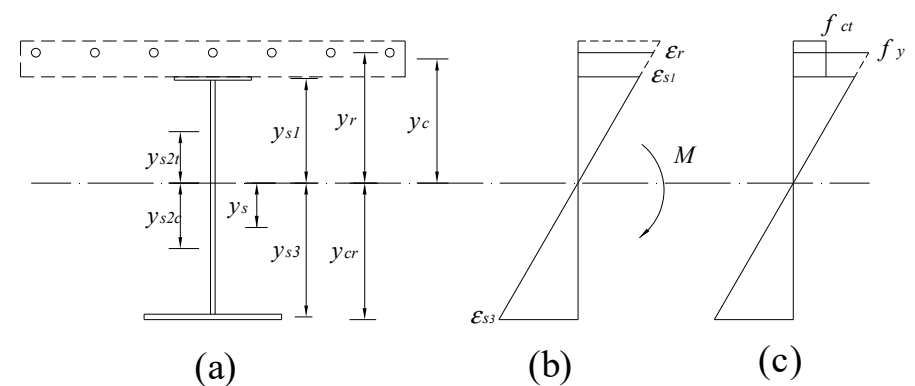

Figure 16. Calculation diagram: (a) crack section; (b) strain distribution; (c) stress distribution.

\section{Conclusions}

In this paper, two types of girder-to-girder joints suitable for lightweight steel-UHPC composite bridges were proposed and tested. The following conclusions can be drawn:

(1) According to the comparative model test, it is observed that the T-shaped joint was superior to the traditional I-shaped joint in terms of crack resistance. The weak interfaces of the T-shaped joint were set in the areas with relatively lower negative bending moment, which could significantly decrease the cracking risk of the joint interface.

(2) The maximum shrinkage strain of reinforced UHPC deck was $164 \mu \varepsilon$ for curing with steam, $173 \mu \varepsilon$ for natural curing, and decreased to zero after steam curing. Hence, steam curing can effectively minimize the shrinkage time of UHPC and reduce the cracking risk. Moreover, the reinforcement had a very large inhibitory effect on UHPC material shrinkage.

(3) The second generation T-shaped joint exhibited better performance than the original scheme.

(4) Based on the analysis of the stiffness, except for the joint interface section, the other sections remained elastic and showed good agreement with the theoretical values; as for the overall deflection prediction, the cracked section could work better on serviceability limit states, and the section of I-shaped steel girder was more suitable for final deflection.

(5) We propose a revised equation for estimating the crack width of the joint interface of steel-UHPC composite beam. It is concluded that the analytical value agrees well with the experimental result.

\section{Patents}

The design schemes described in this article have obtained Chinese invention patents:

(1) Shao, Xudong; Deng, Shuwen; Yan, Banfu. The structure and construction method of negative moment region of lightweight steel-UHPC composite bridge. Patent No.: ZL201610584441.X. (In Chinese)

(2) Shao, Xudong; Qiu, Minghong; Yan, Banfu. Structure of negative moment region of assembled lightweight steel-UHPC composite girders. Patent No.: ZL201820091604.5. (In Chinese) 
Author Contributions: Conceptualization, X.S. and B.Y.; methodology, S.D.; Validation, B.Y. and Y.W.; Formal analysis, S.D.; Writing-original draft preparation, S.D.; Writing-review and editing, S.D., B.Y. and H.L.; Supervision, X.S.; Project administration, X.S.; Funding acquisition, X.S. All authors have read and agreed to the published version of the manuscript.

Funding: This research was funded by the National Key R\&D Program (Grant No.: 2018YFC0705400), the National Natural Science Foundation of China (Grant No.: 51778223), and the Major Program of Science and Technology of Hunan Province (Grant No.: 2017SK1010).

Acknowledgments: The authors would like to express their sincere gratitude to the editor and the anonymous reviewers who significantly enhanced the contents of the study with their insightful comments.

Conflicts of Interest: The authors declare no conflict of interest.

\section{References}

1. Graybeal, B.A. Material Property Characterization of Ultra-High Performance Concrete (No. FHWA-HRT-06-103); Federal Highway Administration, Office of Infrastructure Research and Development: McLean, VA, USA, 2006.

2. Krelaus, R.; Wisner, G.; Freisinger-Schadow, S.; Schmidt, M.; Böhm, S.; Dilger, K. Resistance of Adhesive Bonding of Ultra-High Performance Concrete to Hygrothermal, Corrosive, and Freeze-Thaw Cycling Environments. In Durability of Building and Construction Sealants and Adhesives, 3rd Volume; ASTM International: West Conshohocken, PA, USA, 2010.

3. Paul, S.C.; Babafemi, A.J. A review of the mechanical and durability properties of strain hardening cement-based composite (SHCC). J. Sustain. Cem.-Based Mater. 2018, 7, 57-78. [CrossRef]

4. Meng, W.; Khayat, K.H. Mechanical properties of ultra-high-performance concrete enhanced with graphite nanoplatelets and carbon nanofibers. Compos. Part B Eng. 2016, 107, 113-122. [CrossRef]

5. Meng, W.; Khayat, K.H. Effect of hybrid fibers on fresh properties, mechanical properties, and autogenous shrinkage of cost-effective UHPC. J. Mater. Civ. Eng. 2018, 30, 04018030. [CrossRef]

6. Cao, J.; Shao, X.; Zhang, Z.; Zhao, H. Retrofit of an orthotropic steel deck with compact reinforced reactive powder concrete. Struct. Infrastruct. Eng. 2016, 12, 411-429. [CrossRef]

7. Shao, X.; Yi, D.; Huang, Z.; Zhao, H.; Chen, B.; Liu, M. Basic performance of the composite deck system composed of orthotropic steel deck and ultrathin RPC layer. J. Bridge Eng. 2011, 18, 417-428. [CrossRef]

8. Ebadollah, H.; Sritharan, S.; Rouse, J.M.; Aaleti, S. Bridge Decks with Precast Uhpc Waffle Panels: A Field Evaluation and Design Optimization. J. Bridge Eng. 2016, 21, 04015030.

9. Liu, Y.; Zhang, Q.; Meng, W.; Bao, Y.; Bu, Y. Transverse fatigue behaviour of steel-UHPC composite deck with large-size U-ribs. Eng. Struct. 2019, 180, 388-399. [CrossRef]

10. Ghasemi, S.; Zohrevand, P.; Mirmiran, A.; Xiao, Y.; Mackie, K. A Super Lightweight Uhpc-Hss Deck Panel for Movable Bridges. Eng. Struct. 2016, 113, 186-193. [CrossRef]

11. Deng, S.W.; Shao, X.; Yan, B.F.; Guan, Y.P. Lightweight Steel-Uhpc Composite Bridge with Overall Prefabrication and Fast Erection in City. China J. Highw. Transp. 2007, 30, 159-166.

12. Benjamin, G.A. Structural Behavior of a 2 nd Generation Ultra-High Performance Concrete Pi-Girder; US Department of Transportation Federal Highway Administration: McLean, VA, USA, 2009.

13. Sriram, A.; Petersen, B.; Sritharan, S. Design Guide for Precast Uhpc Waffle Deck Panel System, Including Connections; FHWA-HRT-13-032; US Department of Transportation Federal Highway Administration: Washington, DC, USA, 2013.

14. Vic Perry, F.C.; Eng, P.; Dykstra, D.; Murray, P.; Eng, M.; Rajlic, B.; Halifax, N.S. Innovative Field Cast Uhpc Joints for Precast Bridge Systems-3-Span Live Load Continuous. In Annual Conference of the Transportation Association of Canada; Transportation Association of Canada: Ottawa, ON, Canada, 2010.

15. Graybeal, B. Design and Construction of Field-Cast UHPC Connections; United States Federal Highway Administration: McLean, VA, USA, 2014.

16. Guan, Y.P. Design and Preliminary Experiments of Uhpc П-Shaped Girder Bridge. Master's Thesis, Hunan University, Hunan, China, 2016.

17. Qi, J.; Bao, Y.; Wang, J.; Li, L.; Li, W. Flexural behavior of an innovative dovetail UHPC joint in composite bridges under negative bending moment. Eng. Struct. 2019, 200, 109716. [CrossRef]

18. Tazarv, M.; Saiidi, M.S. UHPC-filled duct connections for accelerated bridge construction of RC columns in high seismic zones. Eng. Struct. 2015, 99, 413-422. [CrossRef] 
19. Shao, X.; Hu, J. The Steel-Uhpc Lightweight Composite Bridge Structures; China Communications Press Co. Ltd.: Beijing, China, 2015.

20. Soren, E.; Müller, C. Autogenous Shrinkage Strain of Ultra-High-Performance Concrete (UHPC); Paper Presented at the Proceedings of the 2nd International Symposium on UHPC; Kassel University press Gmbh: Kassel, Germany, 2008.

21. Ichinomiya, T.; Hishiki, Y.; Ohno, T.; Morita, Y.; Takada, K. Experimental study on mechanical properties of ultra-high-strength concrete with low-autogenous-shrinkage. Spec. Publ. 2005, 228, 1341-1352.

22. Lallemant-Gamboa, I.; Chanut, S.; Lombard, J.P.; Chaignon, J.; Thibaux, T. Formulations, Characterizations and Applications of Ultra High-Performance Concrete. Spec. Publ. 2005, 228, 1221-1236.

23. Fehling, E.; Leutbecher, T.; Bunje, K. Design relevant properties of hardened Ultra High performance concrete. In Int. Symp. on Ultra High Performance Concrete; Kassel University press Gmbh: Kassel, Germany, 2004; Volume 1, pp. 327-338.

24. Schmidt, M.; Fehling, E.; Glotzbach, C.; Fröhlich, S.; Piotrowski, S. Ultra-High Performance Concrete and Nanotechnology in Construction. In Proceedings of the 3rd International Symposium on Uhpc and Nanotechnology for High Performance Construction Materials, Kassel, Germany, 7-9 March 2012.

25. Shao, X.; Pan, R.; Zhan, H.; Fan, W.; Yang, Z.; Lei, W. Experimental Verification of the Feasibility of a Novel Prestressed Reactive Powder Concrete Box-Girder Bridge Structure. J. Bridge Eng. 2017, 22, 04017015. [CrossRef]

26. MOHURD. Reactive Powder Concrete; GB/T 31387-2015, Standardization Administration; Ministry of Housing and Urban-Rural Development of the China: Beijing, China, 2015.

27. Alireza, R. Computer Modeling and Investigation on the Steel Corrosion in Cracked Ultra High Performance Concrete; Kassel University Press GmbH: Kassel, Germany, 2012; Volume 21.

28. Tohru, M.; Brühwiler, E. Tensile Fatigue Behaviour of Ultra-High Performance Fibre Reinforced Concrete (Uhpfrc). Mater. Struct. 2014, 47, 475-491.

29. Luo, J.; Shao, X.; Cao, J.; Xiong, M.; Fan, W. Transverse Bending Behavior of the Steel-Uhpc Lightweight Composite Deck: Orthogonal Test and Analysis. J. Constr. Steel Res. 2019, 162, 105708. [CrossRef]

30. Luo, J.; Shao, X.; Fan, W.; Cao, J.; Deng, S. Flexural cracking behavior and crack width predictions of composite (steel+ UHPC) lightweight deck system. Eng. Struct. 2019, 194, 120-137. [CrossRef]

31. Zhang, Z.; Shao, X.D.; Li, W.G.; Zhu, P.; Chen, H. Axial tensile behaviour test of Ultra High performance concrete. China J. Highw. Transp. 2015, 28, 50-58.

32. Pan, W.H.; Fan, J.S.; Nie, J.G.; Hu, J.H.; Cui, J.F. Experimental study on tensile behavior of wet joints in a prefabricated composite deck system composed of orthotropic steel deck and ultrathin reactive-powder concrete layer. J. Bridge Eng. 2016, 21, 04016064. [CrossRef]

33. Chen, B. Research and Experiment on Bending Behavior of Wet Joints in Lightweight Composite Deck System Composed of Orthotropic Steel and Uhpc Layer. Ph.D. Thesis, Hunan University, Hunan, China, 2018.

34. Li, W. Experimental Research on Static and Fatigue Flexural Performance of Uhpc Layer in Light-Weighted Composite Bridge Deck. Master's Thesis, Hunan University, Hunan, China, 2015.

35. AFGC-SETRA. Ultra High Performance Fibrereinforced Concretes. In Recommendations; AFGC\&SETRA Working Group: Paris, France, 2013; pp. 1-175.

36. Haibin, X.U.; Deng, Z. Cracking Moment and Crack Width of Ultra-High Performance Concrete Beams. J. Harbin Inst. Technol. 2014, 46, 87-92.

37. MOHURD. Code for Design of Concrete Structures Gb50010-2010; Ministry of Housing and Urban-Rural Development of the China: Beijing, China, 2010.

(C) 2020 by the authors. Licensee MDPI, Basel, Switzerland. This article is an open access article distributed under the terms and conditions of the Creative Commons Attribution (CC BY) license (http://creativecommons.org/licenses/by/4.0/). 